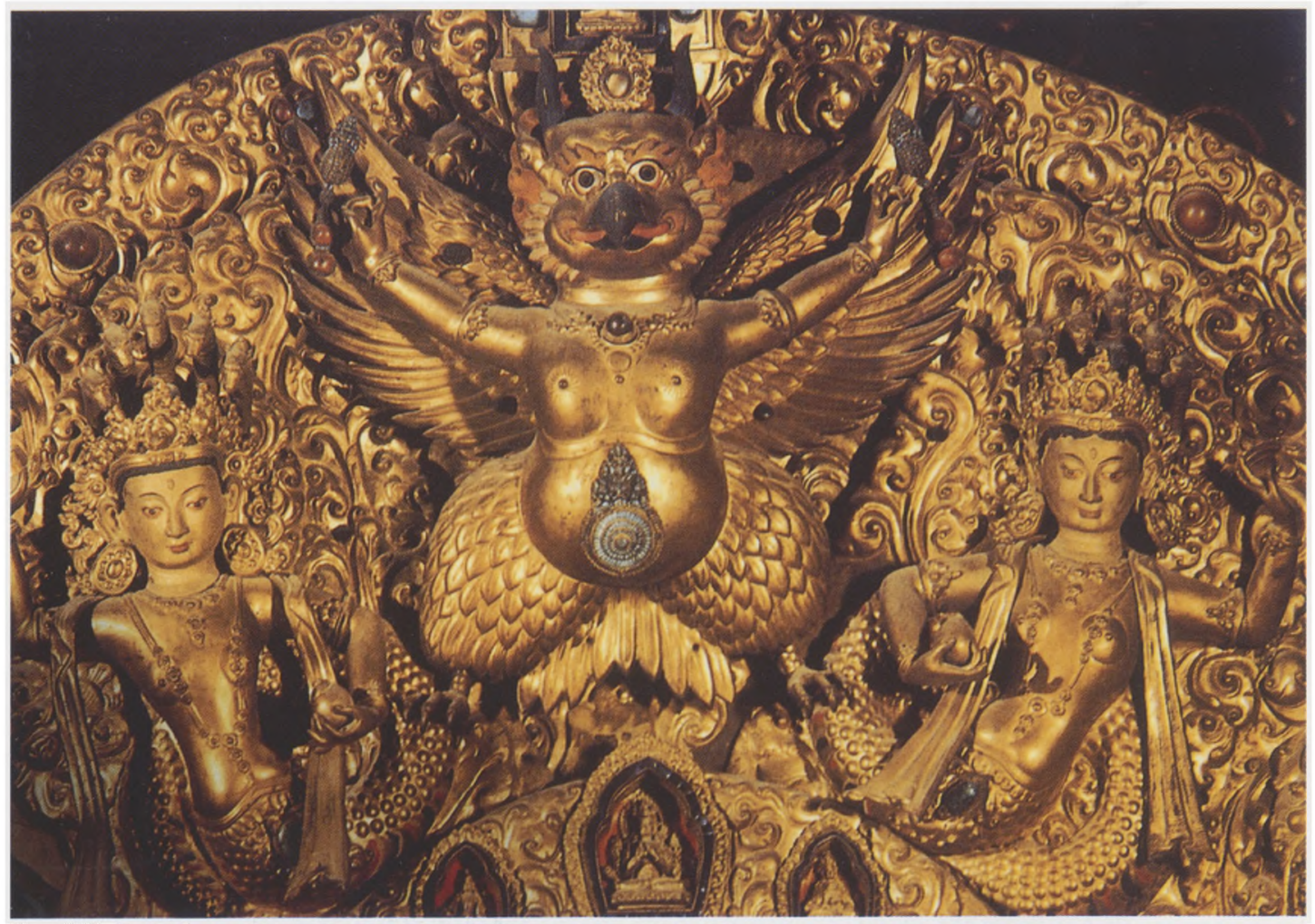

Afbeelding 1

Detail van een grote

prabhamandala. Potala-

paleis, Lhasa, Tibet, 


\section{DE ONTWIKKELING VAN DE PRABHAMANDALA IN DE VROEG-TIBETAANSE KUNST}

De Tibetaanse kunstgeschiedenis is een nog jonge wetenschap. Pas in de loop van de $20^{\mathrm{C}}$ eeuw is men in het westen begonnen met methodisch onderzoek naar stijlontwikkelingen en iconografie. Aanvankelijk bleef dit onderzoek beperkt tot objecten in westerse collecties; pas sinds de jaren tachtig, na de voorzichtige openstelling van Tibet voor westerse bezoekers, kon ook in situ kennis worden genomen van de nog aanwezige objecten, wandschilderingen, etc., die de ravage van de Culturele Revolutie hadden overleefd.

Zo langzamerhand hebben we ons een goed beeld kunnen vormen van de ontwikkeling van de Tibetaanse kunst en van de buiten-Tibetaanse invloeden in de verschillende periodes.

Van groot belang is de zogenaamde Tweede Verspreiding van het boeddhisme geweest. Het boeddhisme werd in de $7^{\mathfrak{c}}$ eeuw in Tibet geïntroduceerd en heeft daar enkele eeuwen onder het patronaat van de Tibetaanse koningen kunnen bestaan. In de $9 \mathbf{}$ eeuw werd deze periode abrupt beëindigd, om pas aan het eind van de $10^{c}$ eeuw weer op te leven. Vanuit India kwam een nieuwe stimulans, temeer omdat daar de vanuit het westen oprukkende islamitische legers zowel het oude hindoeïsme als het boeddhisme dreigden te overspoelen. De grote kloosters in het noordwesten van India als Vikramashila, Odantapuri en Nalanda werden verwoest en vele monniken weken uit naar het noorden, eerst naar Nepal, maar later ook, over de Himalaya, naar Tibet. Zij namen de Indiase Pala-cultuur met zich mee, in de vorm van sculpturen en geschriften, maar vooral ook van ideeën. Deze 'Tweede Verspreiding van het Boeddhisme' heeft in Tibet tot de zo typische kloostercultuur geleid, die tot het midden van de $20^{c}$ eeuw heeft bestaan. De gewelddadige annexatie van Tibet door China heeft deze eeuwenoude en unieke cultuur voor altijd aangetast.

Als kunsthistoricus en kunsthandelaar heb ik me vele jaren bezig gehouden met de Tibetaanse kunst, in de breedste zin van het woord. Oneindig veel beeldjes zijn gedetermineerd, bekeken naar stijl en voorzien van een datering, vele thangka's zijn minutieus geanaliseerd en beschreven, en vele objecten van de fascinerende materiële cultuur van het Tibetaans-boeddhisme zijn door mijn handen gegaan. Wat mij op een gegeven moment verbaasde is dat een belangrijk element in schilderingen en sculpturen, namelijk de prabhamandala, in de literatuur altijd als een soort stiefkindje is behandeld. In de meeste verhandelingen worden de belangrijkste godheden en andere figuren iconografisch en stilistisch uitvoerig behandeld, terwijl de triomfboog, waardoor de afgebeelde figuren omlijst worden, volstrekt genegeerd wordt. Op z'n best wordt deze omschreven als 'afgeleid van het Indiase Palaidioom'. Omdat ik door de jaren heen vele koorbeelden van prabhamandala's 29:29pM heb gezien - van verschillende materialen en van uiteenlopende periodes ree access 
raakte ik geïntrigeerd door hun verschillende vormen, die wijzen op een heel aparte ontwikkeling.

\section{Definitie}

Als we denken aan een prabhamandala in de Tibetaanse kunst, hebben we een algemeen idee over de vorm: een boogvormige troon-achtergrond, die de afgebeelde godheden of vergoddelijkte personen omringt.

Allereerst zou ik een onderscheid willen maken tussen het woord prabhamandala en het woord toran. Dit zijn twee termen die in veel gevallen aan hetzelfde concept worden gegeven. ${ }^{1}$

Volgens mij dient het woord 'prabhamandala' (letterlijk vertaald: 'boog/cirkel van licht') gebruikt te worden voor de gehele constructie van de achterwand, d.w.z.: de rugleuning van de troonzetel waarop de godheid of een heilig verklaard persoon zit of staat, samen met de triomfboog daar bovenop. Men ziet altijd een verdeling tussen beide delen, in de vorm van een liggende balk, die - afhankelijk van de periode - heel prominent of bijna niet uitgebeeld wordt. Het woord 'toran' zou alleen gebruikt moeten worden voor de boog, boven de dwarsbalk.

In het algemene concept bestaat een toran uit een boog, die beheerst wordt door een dramatische garuda-figuur bovenaan, met vleugels, klauwen en een slang in zijn bek. Deze garuda wordt geflankeerd door twee naga's, met menselijke bovenlijven en slangen-onderlijven (afb. 1). Het derde element van een toran zijn de twee makara's (mythologisch watermonster met een krokodillensnuit), die op de dwarsbalk rusten. Zij kijken naar buiten en hebben staarten die uitwaaierende spiralen vormen en soms de gehele oppervlakte kunnen vullen. ${ }^{2}$ De drager hieronder (in feite de rugleuning van de troonzetel) bestaat aan beide zijden uit een aantal dieren: hier zie je twee olifanten met op hun rug twee leeuwen, die elk naar buiten lijken te springen. Ik wil hier niet de diepere symboliek van dit concept behandelen, die in het Tibetaans rgyan drug rgyab yol (de 'troonrug van de zes ornamenten') ${ }^{3}$ wordt genoemd, maar nu juist eens kijken naar de stilistische ontwikkeling van deze gecompliceerde compositie.

De 'klassieke' vorm van de prabhamandala, zoals hierboven beschreven, blijkt in Tibet pas vanaf de $14^{\mathrm{c}}$ eeuw te bestaan. Tibetaanse prabhamandala's van vroegere datum, zeg maar van de $11^{\mathrm{e}}$ tot de $14^{\mathrm{e}}$ eeuw, zijn volstrekt anders. De garuda en de makara's zijn anders, er zijn geen naga's te zien, en in veel gevallen van het vroegere type zien we geen garuda in de top, maar een kirtimukha, een monsterkop, duidelijk gebaseerd op Indiase prototypes, net zoals vele andere vroege Tibetaanse stilistische elementen herleid kunnen worden op Indiase voorbeelden.

\section{De Indiase voorbeelden}

In de Indiase artistieke traditie heeft bijna elk metalen of stenen beeld een prabhamandala. Soms hebben deze prabhamandala's aan de bovenzijde een kirtimukha, het gelaat van een mythologisch wezen, dat ongetwijfeld een apotropeïsche (afwerende of bezwerende) functie had. ${ }^{4}$ Van oorsprong was het stilistische thema op een aureool boven een godheid de afbeelding van ve $_{1: 29: 29 \mathrm{pm}}$ twee hemelse figuren, apsara's, die eer betuigen aan de centrale godheid. 5 ree access 

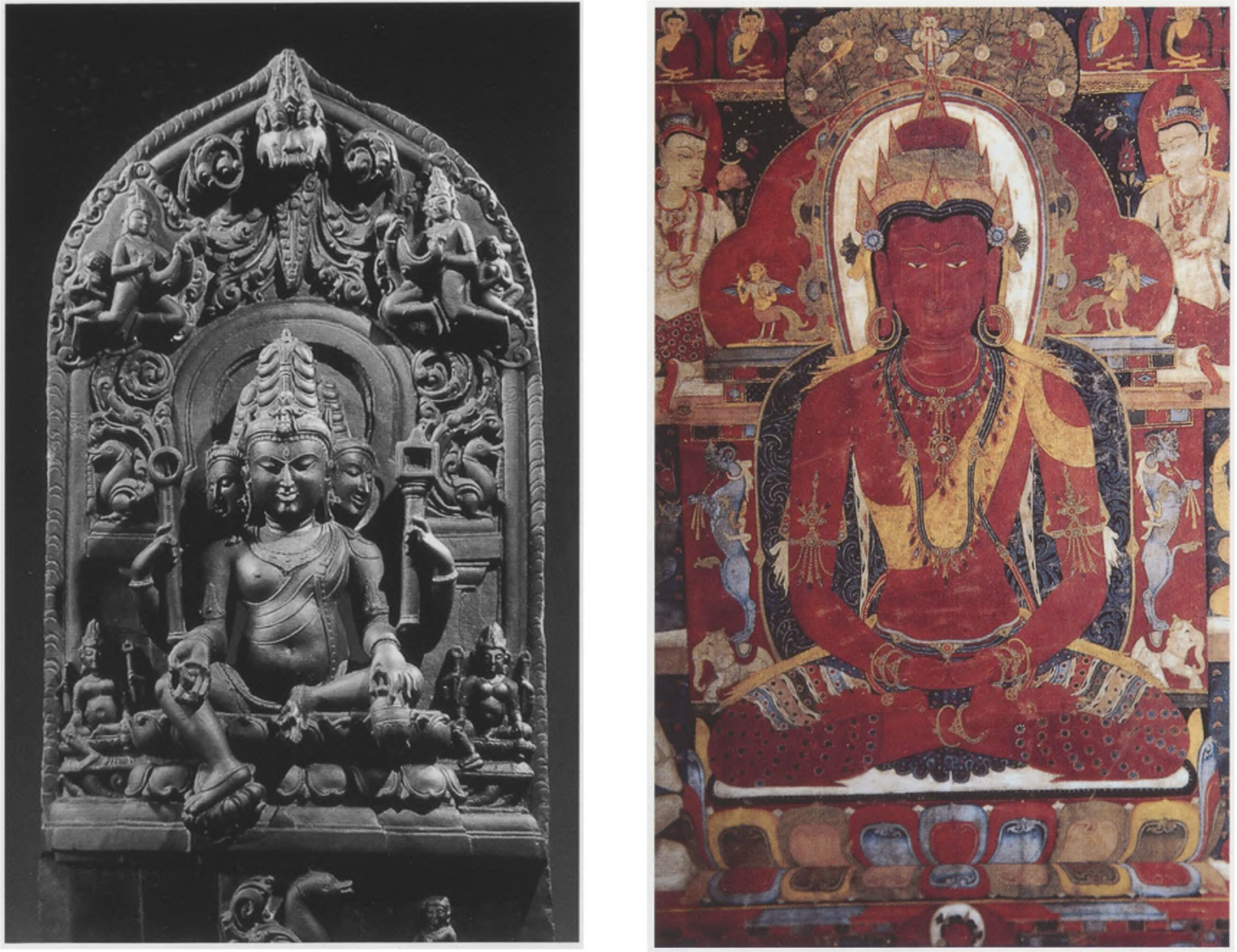

Afbeelding 2 (links) Zittende Kuvera. Noordoost-India (Pala), ca. 11 eeuw

\section{Afbeelding 3}

Thangka van de Boeddha Amitayus. Tibet, laat $13^{\mathrm{e}}$ - vroeg $14^{e}$ eeuw. Privé collectie
In Noordoost-India, gedurende de Pala-dynastie, komen we - in ieder geval bij stenen stèles - een combinatie van deze apsara's met een centrale kirtimukha tegen ( $\mathrm{afb}$. 2). Bronzen beelden uit deze periode hebben echter alleen een kirtimukha. Een kirtimukha kenmerkt zich door uitpuilende ogen en twee of drie decoratieve lijnen, die uit zijn bek komen.

Aan de onderkant van de toran, rustend op de dwarsbalk, zien we makara's of vogels. Dit kunnen pauwen, ganzen en ook soms kinnara's (mythologische hybride mensvogel) zijn, die veelal naar buiten kijken, terwijl hun staarten uitmonden in soms spectaculaire spiralen.

Hieronder heeft het draaggedeelte ook een vastomlijnd patroon. Rechts en links zien we twee op hun achterpoten staande leeuwen (vyala's), meestal met hun kop naar buiten gericht en - heel typisch - met de staart tussen hun achterpoten gekruld. Deze staan op kleinere olifanten.

Zoals hier beschreven, hebben we het klassiek-Indiase type, dat gediend heeft als prototype voor de Tibetaanse kunst.

\section{De eerste fase in Tibet}

De vroege Tibetaanse 'kopieën' van deze Indiase prabhamandala's zijn in sommige gevallen getrouwe reproducties van het Indiase prototype. Maar in vele gevallen worden de verschillende stijlen door elkaar gehusseld. De Tibetaanse kunstenaars begrepen duidelijk niet de ins and outs yan de Indiase 20 01:29:29pM voorbeelden. 


\section{Afbeelding 4} Verzameling khyungtoksha's.

Maxwell-collectie, San Fransisco

(pagina 11)

Afbeelding 5 (boven)

Boekplank. Tibet,

Ca. $12^{\mathrm{e}}$ eeuw.

Collectie K., Duitsland.

Afbeelding 6

Kopse zijde van een

boekplank. Tibet,

ca. $13^{e}$ eeuw.

Collectie Astamangala, Amsterdam

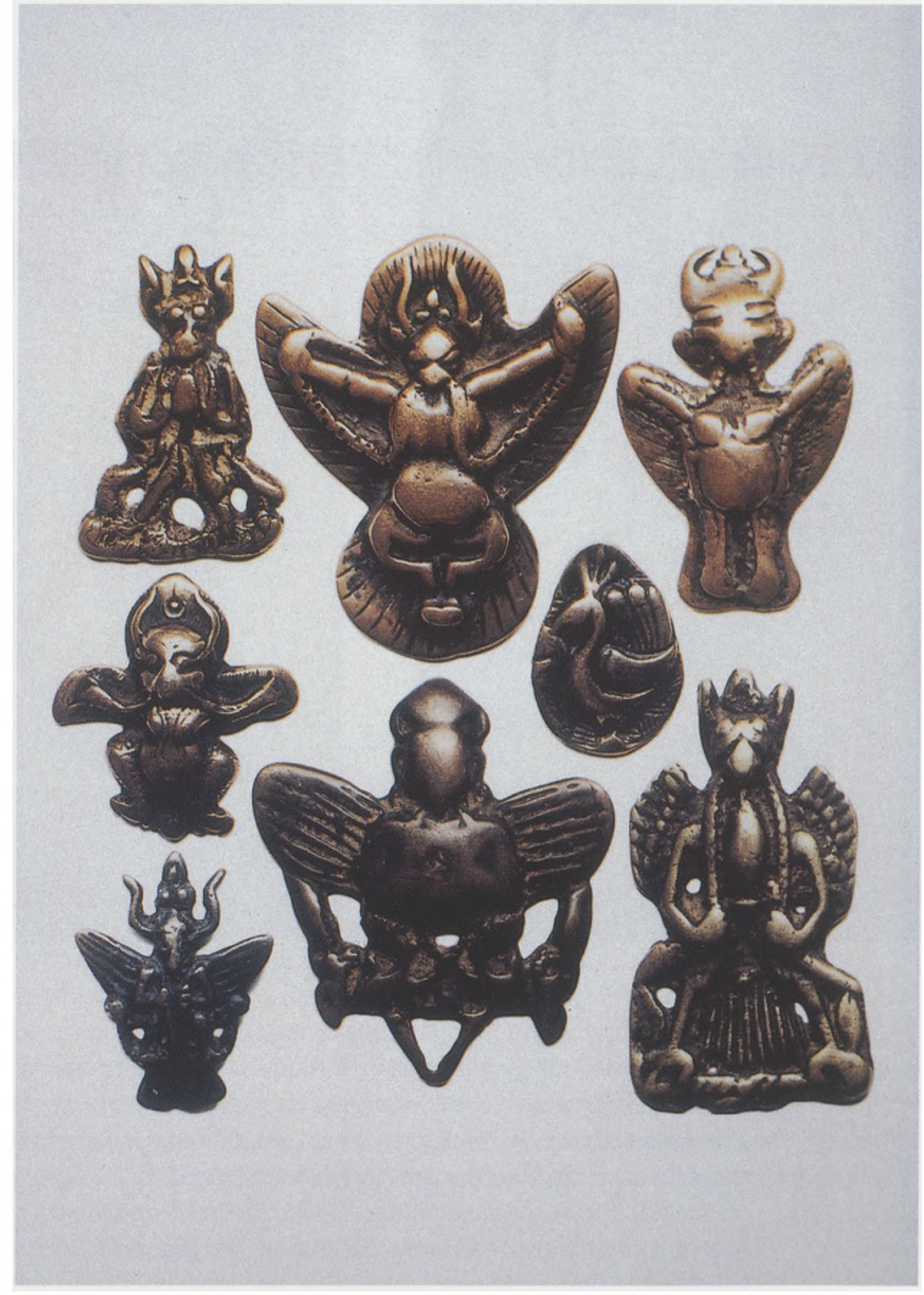

Opvallend is dat in veel gevallen de klassieke kirtimukha wordt vervangen door iets compleet anders: een gevleugeld wezen, dat een slang (of, gestileerd, alleen maar twee stokken, die voortkomen uit de mandorla van de godheid) ${ }^{6}$ voor zijn lichaam in zijn klauwen houdt. In de westerse literatuur wordt dit wezen altijd een 'garuda' genoemd. ${ }^{7}$ Volgens mij is dit absoluut geen garuda. Dit wezen heeft vleugels, maar ook zeer prominent afgebeelde hoorns, en als men het goed bekijkt, lijkt het in het geheel niet op de klassieke garuda, zoals die in India wordt afgebeeld. Bovendien is het onverklaarbaar waarom zonder enig precedent een garuda, een typisch hindoe-icoon, plotseling in het Tibetaans-boeddhistische idioom zou opduiken. Ik ben daarom van mening dat dit figuur van puur-Tibetaanse, en zeer waarschijnlijk van pre-boeddhistische oorsprong is. Amy Heller ${ }^{8}$ suggereert dat deze

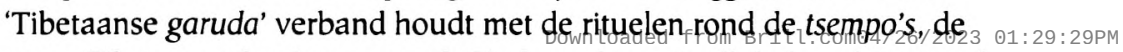
vroeg-Tibetaanse koningen van de Yarlung-dynastie. Ik heb verbijsterend ree access 


\section{1}
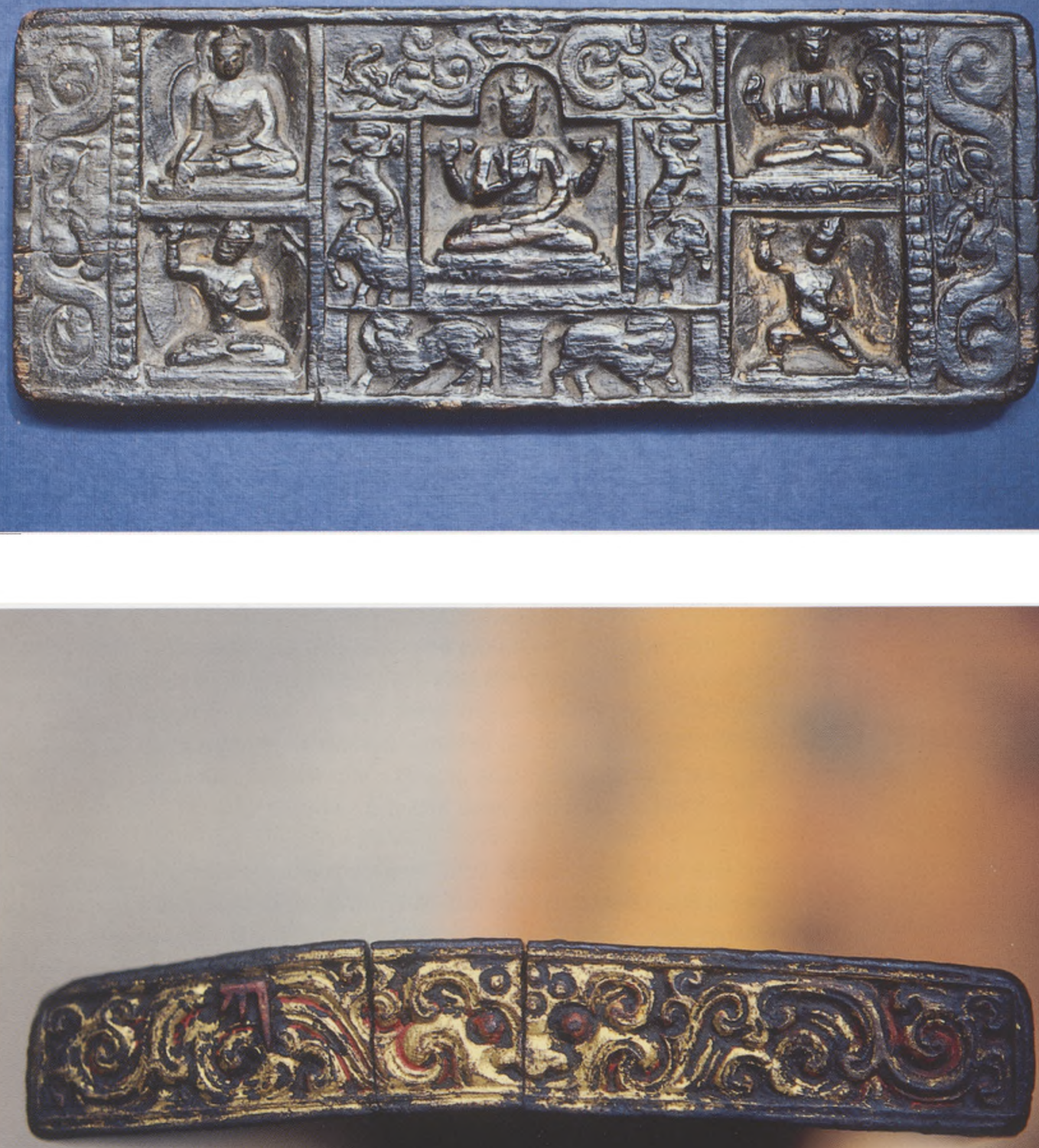
gelijkende afbeeldingen gevonden in de zogenaamde toksha's, de befaamde Tibetaanse metalen amuletten, die - zoals Tibetanen geloven - uit de hemel zijn gevallen en worden geassocieerd met de donder en daardoor uitermate krachtige amuletten zijn (afb. 3). Toksha's kunnen van pre-boeddhistische of vroeg-boeddhistische oorsprong zijn, maar het is nog steeds een groot probleem deze fascinerende objecten preciezer te dateren. In de literatuur wordt gesuggereerd dat dit wezen van oorsprong een stierenkop had, wat zich later heeft ontwikkeld tot een vogelkop. ${ }^{9}$ Dit zou de twee hoorns verklaren. In ieder geval hebben veel van deze toksha's dezelfde vorm als de gevleugelde wezens bovenaan de vroeg-Tibetaanse prabhamandala's. Ik stel daarom voor om deze bij hun Tibetaanse naam khyung te noemen en niet de hindoe-naam garuda te gebruiken. Dit wezen is een puur Tibetaans, apotropeïsch mythisch dier dat dient als bescherming tegen het kwade, net zoals de kirtimukha in het Indiase idioom, wat een mogelijke verklaring voor de verwarring kan zijn. Wel denk ik dat zowel de khyung als de garuda ooit een gemeenschappelijke oorsprong hebben gekend, ergens in Centraal-Azië of Iran, en beide werden geassocieerd met de hemel en de zon. ${ }^{10}$

Een heel mooi voorbeeld voor deze ontwikkeling is een vroege, ongeveer $12^{\mathrm{c}}$ eeuwse boekplank, ${ }^{11}$ waarvan het snijwerk op de buitenzijde een goede illustratie geeft van wat ik met bovenstaande bedoel (afb. 4).

De prabhamandala rond de centrale figuur is duidelijk: boven is een khyung, er zijn twee makara's op de dwarsbalk, en twee vyala's staan op olifanten, die het geheel dragen. Hier hebben we dus - uitgezonderd de khyung - een voorbeeld van een getrouwe kopie van het Indiase Pala-prototype. Maar als we nauwkeuriger kijken, zien we dat de oorspronkelijke kirtimukha verhuisd is van boven in de toran naar de buitenkant van de boekenplank, en als zodanig nog steeds fungeert als beschermer van het boek (afb. 5). Als we nu kijken naar andere boekplanken uit deze periode, zien we dat in een volgende ontwikkeling de kirtimukha zelfs nog verder verhuist, namelijk naar de kopse zijkant van de plank, de kant die men ziet als het boek in de boekenkast ligt. We moeten ook dit duidelijk zien als een symbool van bescherming, wat door iedereen - ook al is dit symbool veel ouder dan het boeddhisme in Tibet - als zodanig werd herkend en begrepen.

In de vroege fase van de Tibetaanse kunst zien we geen verandering bij de makara: net als bij de vogels, die op deze plek van de toran afgebeeld kunnen worden, is hun belangrijkste kenmerk de staart, die uitloopt in uitbundige krullen. Het enige verschil met de Indiase voorbeelden is dat in Tibetaanse torana's deze makara's c.q. vogels zowel naar buiten als naar binnen gekeerd afgebeeld kunnen worden.

Het motief van een dier met een krullende staart kan in de vroeg-Tibetaanse kunst ook individueel afgebeeld worden. Juist op boekplanken ziet men vaak vogels of makara's met hun wijd uitkrullende staarten als hoofdmotief (afb. 6). ${ }^{12}$ Hetzelfde geldt voor de uitbeelding van de vyala's, de staande leeuwtjes: hier is geen noemenswaardige verandering ten opzichte van de Indiase prototypes. Alleen kunnen ook zij, net als de makara's of vogels zowel naar binnen als naar buiten gekeerd worden afgebeeld. ${ }^{13}$

De kirtimukha's verdwijnen in de latere Tibetaanse kunst niet, maar gaan juist een geheel eigen leven leiden. Heel vaak worden zij afgebeeld, enigszins veranderd en duidelijk aangepast aan de Tibetaanse khyung namelijk met hoorns, juwelen of het embleem van de zon en de maan op het hoofdien metcess 

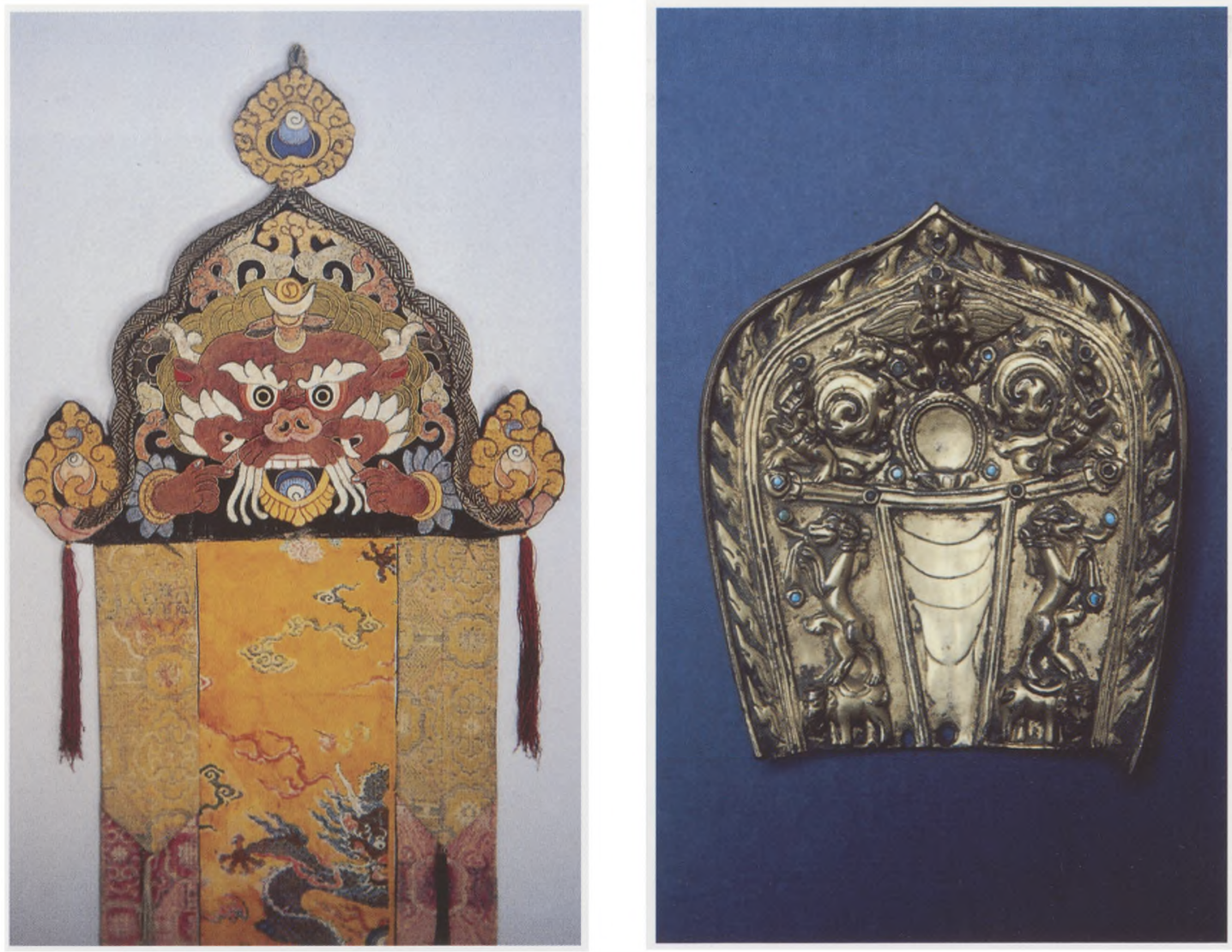

Afbeelding 7 (links) Pilaarbanier met kirtimukha.

Tibet, $19^{e}$ eeuw.

Newark Museum,

Newark

\section{Afbeelding 8}

Prabhamandala, vuurverguld brons. Tibet, $13^{e}-14^{e}$ eeuw. Collectie Astamangala, Amsterdam kleine handjes, die een gestileerde slang vasthouden, net zoals de Tibetaanse khyung. Zij worden beschouwd als beschermers tegen het kwaad. We komen ze tegen op kapitelen (altijd uitkijkend naar buiten), op pilaardecoraties en op allerlei andere rituele of huis-tuin-en keuken objecten, zoals tafels (afb. 7) en kasten.

Op stilistisch gebied verandert er ook iets: de vorm van de prabhamandala wordt gaandeweg ronder en krijgt aan de bovenzijde een punt. Dit type heeft dan een buitenrand van vlammen en het is aannemelijk dat deze vorm afgeleid is van Centraal-Aziatische en/of Chinese voorbeelden, waar deze al eeuwen met een vlammenrand bestond. ${ }^{14}$

De tempel van Drathang, aan de zuidoever van de Yarlung-rivier in CentraalTibet, is in deze context interessant. De befaamde $11^{\mathrm{e}}$ eeuwse wandschilderingen zijn in een puur Indiase Pala-stijl geschilderd, terwijl de in stucco-reliëf uitgevoerde aureolen van de (nu verwoeste) beelden een fantastisch voorbeeld zijn van de Centraal-Aziatische en/of Chinese invloed in deze periode (afb. 8). ${ }^{15}$

Hiermee hebben we in een notendop de situatie van de vroeg-Tibetaanse kunst, met betrekking tot de prabhamandala, ten tijde van de Tweede Verspreiding van het boeddhisme. In Tibet worden de Indiase voorbeelden gekopieerd, maar de kirtimukha wordt vervangen door de puur-Tibetaanse khyung. Ook wordt de vorm van de boog anders onder invloed van Centraal $5: 29 \mathrm{PM}$ Aziatische en Chinese invloeden. 


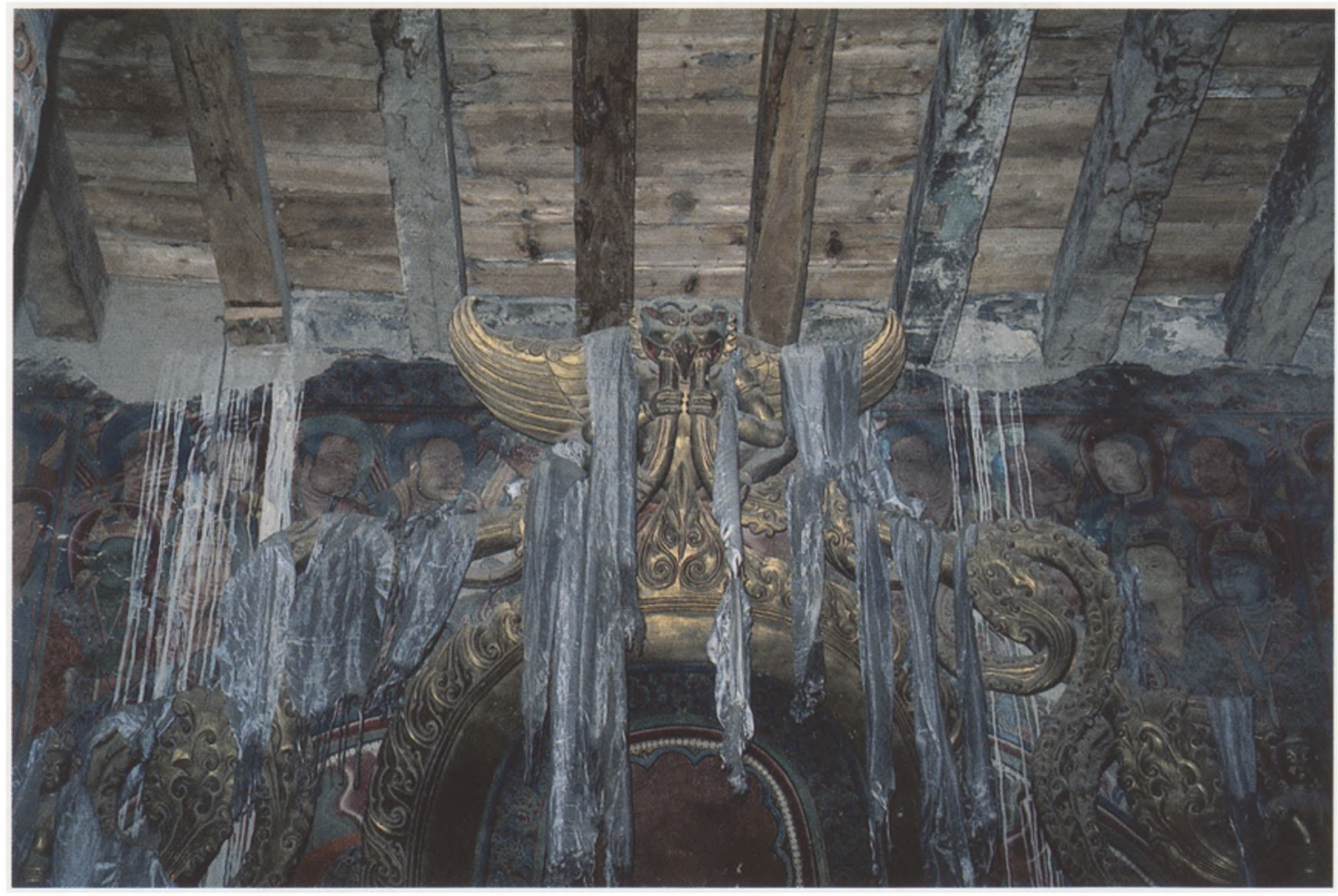

\section{De tweede fase}

Afbeelding 9 Bekroning van een prabhamandala. Drathang-tempel, Tibet, $11^{e}$ eeuw
De tweede fase - en daarmee bedoel ik de overgang naar het 'klassieke' type van prabhamandala, dus met een èchte garuda, en met naga's en makara's komt met een plotselinge en erg sterke instroom van Newari kunstenaars naar Tibet. In de $13^{e}$ en $14^{e}$ eeuw heerste de Sakya-kloosterorde over Tibet, gesteund door de Mongoolse Grote Khans, van welke Kubilai de bekendste is, gezien zijn relatie met Marco Polo. Later, toen de Mongolen China hadden veroverd, werden zij de keizers van de Mongoolse Yuan-dynastie.

Vanuit Nepal, dat toen (en nog steeds trouwens) beroemd was vanwege zijn artistieke tradities, werden kunstenaars uitgenodigd en in dienst genomen om in Tibet te komen werken en daar de vele nieuw gebouwde tempels te decoreren, vaak met Chinese ondersteuning en financiële hulp. Vanuit Tibet gingen deze kunstenaars verder naar China, om in de Chinese hoofdstad in de keizerlijke werkplaatsen te werken, zoals de beroemd geworden Aniko. In het begin van de $14^{\mathrm{e}}$ eeuw keerde een groot aantal van deze kunstenaars terug naar Tibet, opnieuw op uitnodiging, om bijvoorbeeld in het Zhaluklooster, vlak bij Shigatse, te werken. Dit beroemde klooster beleefde in deze periode een bloeiperiode ${ }^{16}$ en werd door de Chinese keizers met rijke donaties bedeeld, zodat het zich de sjieke Nepalese kunstenaars van het Chinese hof kon permitteren.

Vanaf de $13^{\mathrm{e}}$ eeuw zien we voor de tweede keer een fundamentele verandering optreden in de vorm van de prabhamandala: de dieren die de toran $\eta_{1: 29: 29 \mathrm{PM}}$ ondersteunen worden meer 'levend' en dynamisch. De staande vyala'sa free access 
Afbeelding 10 Thangka van de Groene Tara. Centraal-Tibet, derde kwart $13^{\circ}$ eeuw. Cleveland Museum of Art

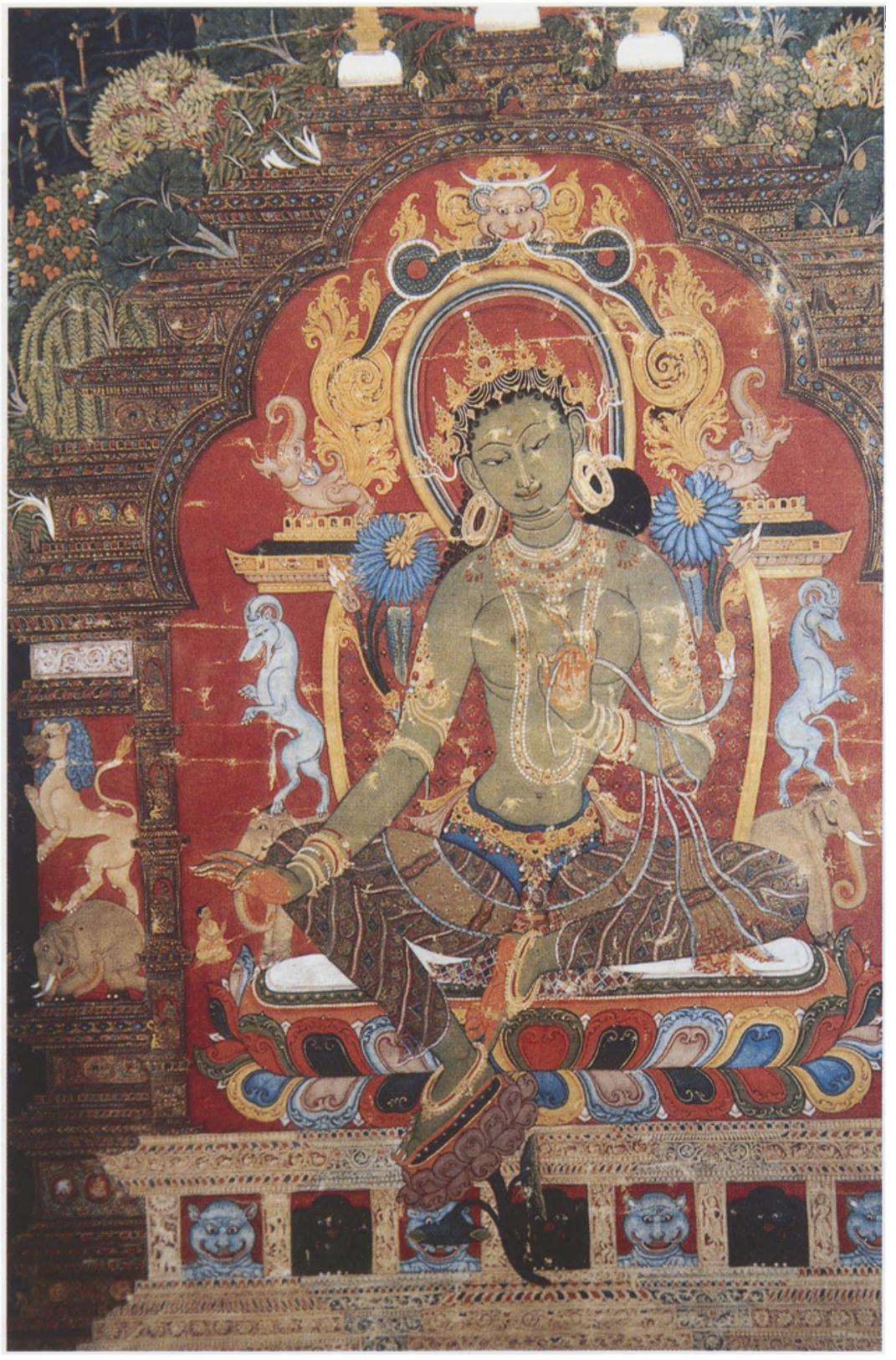

worden nu ingeruild voor sneeuwleeuwen, die naar buiten springen, meestal met een menselijk figuur op hun rug (afb. 9). Een prachtig voorbeeld voor deze fase is de beroemde thangka van de Groene Tara in het Cleveland Museum, die door sommigen toegeschreven wordt aan Aniko zelf. ${ }^{17}$ De prabhamandala rond de centrale figuur is zeer complex. Er zijn twee dragersgroepen aan beide zijden van de Groene Tara. De 'binnen'-groep is een getrouwe weergave van de klassieke Pala-voorbeelden met staande vyala's, terwijl de 'buiten'-groep reeds de nieuwe Nepalese stijl, met springende leeuwtjes, laat zien.

De dwarsbalk tussen het dragende gedeelte en de toran blijft bestaan, maar wordt minder geprononceerd. De khyung aan de bovenzijde verandertiange access 


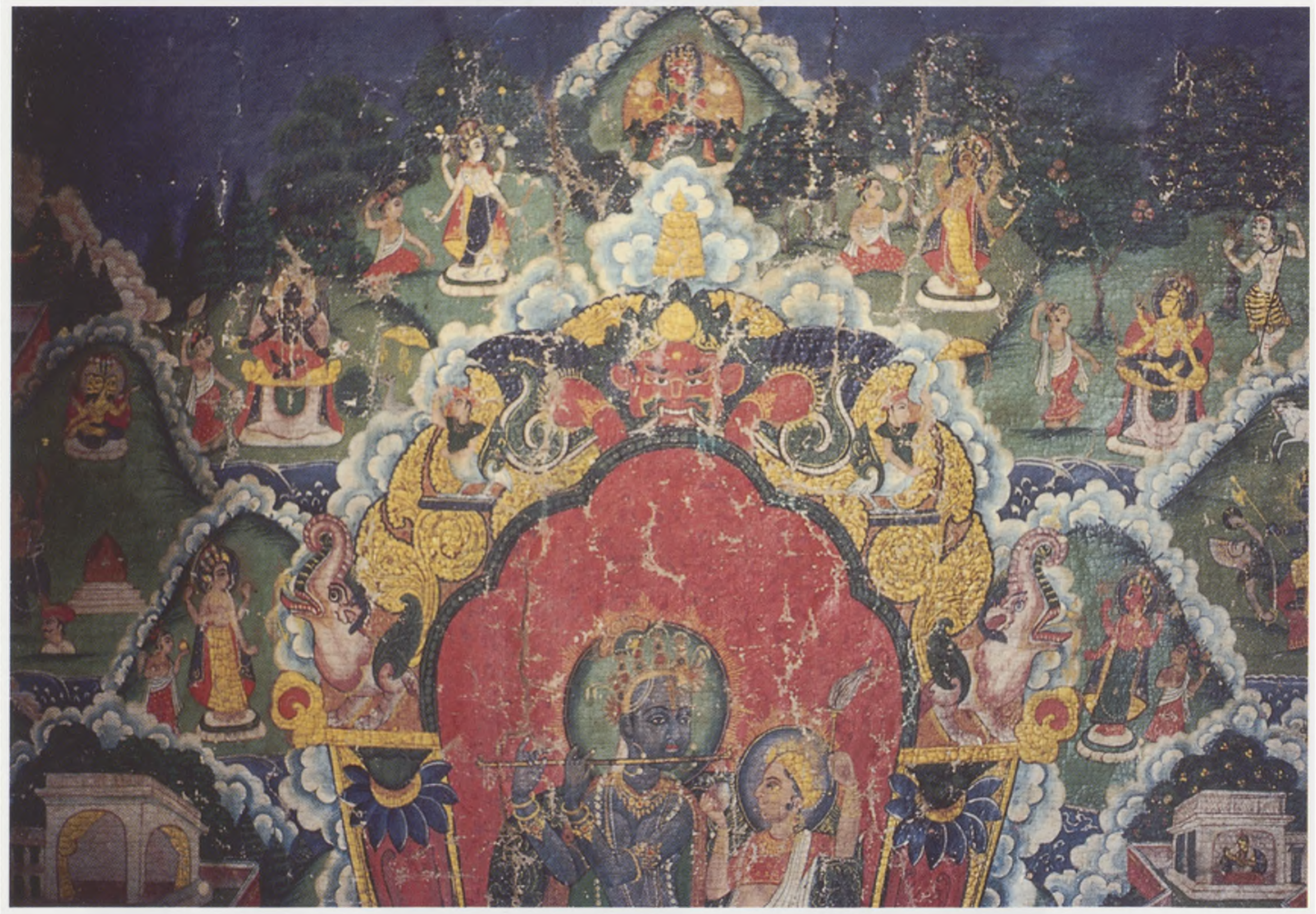

Afbeelding 1

Detail van een paubha van Krishna Venugopala. Nepal, $19^{\circ}$ eeuw. Collectie Astamangala, Amsterdam zaam in een 'echte' garuda, helemaal volgens het hindoe-idioom. Bovendien wordt vanaf de $13^{\mathrm{e}}$ eeuw de slang steeds dikker (afb. 10), en hieruit ontwikkelen zich uiteindelijk twee aparte nagaraja's, aan weerszijden van de garuda, die daarentegen een andere slang weer in zijn bek en klauwen houdt. De makara's blijven hetzelfde, maar worden wel realistischer en levendig, terwijl de variatie makara/vogel verdwijnt: vanaf deze tijd zien we alleen maar de makara afgebeeld.

Metalen prabhamandala's uit deze periode blijken ook niet meer, zoals voorheen, gegoten, maar voor het merendeel gedreven uit (vuurverguld) koperplaat. Ook dit is een techniek afkomstig uit Nepal. Tot in de $20^{\mathrm{e}}$ eeuw zal dit type prabhamandala gebruikt blijven, zonder noemenswaardige verandering.

In dit verhaal is een $19^{e}$ eeuwse Nepalese paubha intrigerend. Afgebeeld is een typisch hindoeïstische voorstelling (afb. 11), met in het midden Krishna als Venugopal ('de fluitspeler') in gezelschap van zijn vriendin Radha.

Rondom hem zien we de verschillende avatara's van Vishnu. Verder zijn de belangrijke goden als Shiva en Brahma ook afgebeeld. Op deze paubha is een 'normaal' type toran gebruikt, maar tot mijn verbazing zien we de terugkeer van de oude vertrouwde kirtimukha. Juist in de Nepalese kunst zouden we normaal gesproken een garuda bovenin de toran verwachten. Met dit 2023 01:29: 29pM voorbeeld is de cirkel weer helemaal rond. 


\section{Literatuur}

T. Akiyama en S. Matsubara, Arts in China: Buddhist Cave Temples, New Researches, Tokyo, 1969.

T. Anninos, The Ancient Amulets of Tibet - Thokcha, San Franscisco, 1999.

J. Casey Singer,' An Early Tibetan Painting Revisited: The Astamahabhaya Tara in the Ford Collection', in Orientations, October 1998, pp. 65-73.

A. Heller, Tibetan Art: Tracing the Development of Spiritual Ideals and Art in Tibet. 6002000 A.D., Milaan, 1999.

M. Henss, 'The Eleventh-century Murals of Drathang Gonpa', in Tibetan Art, towards a Definition of Style, London, 1997.

S.L. Huntington en J. C. Huntington, Leaves from the Bodhi Tree: the Art of Pala India $\left(8^{\text {th }}-12^{\text {th }}\right.$ centuries) and its International Legacy, Dayton, 1990.

S.M. Kossak en J. Casey Singer, Sacred Visions - Early Paintings from Central Tibet, New York, 1998.

H. Kreijger, 'Mural Styles at Shalu', in Tibetan Art, towards a Definition of Style, London, 1997.

Palast der Götter, Berlijn, 1991.

H.R. Ray, K. Khandalavala en S. Gorakshkar, Eastern Indian Bronzes, New Delhi, 1986.

G. Tucci, Transhimalaya, London, 1973.

R. Vitali, The Early Temples of Central Tibet, London, 1990.

H. Weihreter, Schmuck aus dem Himalaya, Graz, 1988.

\section{Noten}

1. Bijvoorbeeld Beer, pp. 88-90.

2. Bijvoorbeeld Kossak en Singer, p. 125, no. 30; p. 145, no. 37.

3. Beer, p. 90.

4. Palast der Götter, p. 115, no. 116, no. 64 .

5. Palast der Götter, p. 88, no. 42 en p. 203, no 137.

6. Kossak en Casey, p. 119, no. 28.

7. Bijvoorbeeld Beer, p. 90; Kossak en Casey, p. 124, etc.

8. Heller, p. 54. Zij refereert aan een ongepubliceerde scriptie van D. Martin, 'Birdhorns', in The Emergence of Bon and the Tibetan Polemical Tradition, Indiana, 1991.

9. Tucci, p.36; Anninos, no. 23; Weihreter, p. 55 ff. en 238-241.

10. Bijvoorbeeld T. Anninos, Lcog chag, NewYork, 1999, p. 13.

11. Collectie K., Duitsland, afm. $54 \times 16 \mathrm{~cm}$. De afbeelding op de plank is, zover ik weet, uniek en derhalve een belangrijk element in deze ontwikkeling.

12. Bijvoorbeeld Casey Singer, fig. 4; Heller, p. 54.

13. Kossak en Casey Singer, no. 24, 27, en $30 \mathrm{ff}$.

14. Zie bijvoorbeeld de beroemde grottencomplexen langs de Zijderoute, zoals de Mogao-grotten bij Dunhuang en de Yungang-grotten bij Datong in China. Zie Akyiyama en Matsubara, p. 63, pl. 38; p. 77, pl. 129, en p. 135, pl. 121.

15. Vitali, p. 49 ff.; Henss, p. 163, pl. 175.

16. Vitali, p. 91 ff.; Kreijer, p. $170 \mathrm{ff}$.

17. Kossak en Casey Singer, pp. 144-146. 